\title{
Number and relative size of thenar motor units in ALS patients: application of the adapted multiple point stimulation method
}

\author{
F.C. Wang, P.J. Delwaide* \\ University Department of Neurology, Hôpital de la Citadelle, Bld du $12^{\circ}$ de Ligne 1, B-4000 Liège, Belgium
}

Accepted for publication: 8 October 1997

\begin{abstract}
In the present study, the adapted multiple point stimulation (AMPS) method was first applied to median innervated thenar muscles in 22 amyotrophic lateral sclerosis (ALS) patients who did not received any treatment. In all patients, a motor unit number estimate (MUNE) and an average surface-recorded motor unit action potential (S-MUAP) size have been derived even if the denervation was severe; and the results were reproducible. The thenar MUNE was less than the normal lower limit for age in 17 patients, and the mean MUNE (67.1 \pm 90.6 ) was significantly different from that estimated in control subjects $(263.3 \pm 116.8)$. The mean S-MUAP size in the 22 ALS patients was $352.9 \pm 328.4 \mu \mathrm{V} \cdot \mathrm{ms}$ versus $94.1 \pm 30.3 \mu \mathrm{V} \cdot \mathrm{ms}$ in healthy volunteers. A control AMPS was achieved in 8 patients after 2 and 6 months of a glutamate-release antagonist (riluzole) treatment. The mean loss of motor units, based on control thenar MUNEs realized after 6 months of treatment, was 53\%. In conclusion, we propose AMPS as a manageable, reproducible and non-invasive procedure which permits one to quantify peripheral denervation and to appreciate the effectiveness of collateral reinnervation in ALS patients. (C) 1998 Elsevier Science Ireland Ltd.
\end{abstract}

Keywords: Surface-recorded motor unit action potential (S-MUAP); Motor unit number estimate (MUNE); Amyotrophic lateral sclerosis (ALS); Adapted multiple point stimulation method (AMPS)

\section{Introduction}

Electromyography (EMG) is useful in the diagnosis of amyotrophic lateral sclerosis (ALS) (Lambert, 1969; Cornblath et al., 1992) but provides little information for adequate assessment of amyotrophy and its course. Other electrophysiological techniques are, however, available to study quantitatively pathophysiological changes in ALS muscles such as motor unit loss and the size increase of the remaining motor units (Brown and Jaatoul, 1974; Swash and Schwartz, 1982; Stålberg and Sanders, 1984; Dantes and McComas, 1991; Bromberg, 1993). All these methods should be of clinical interest in monitoring the patients' clinical course and in assessing the efficacy of various treatments. Unfortunately, most of these techniques are too sophisticated for routine clinical use or are not completely free of methodological biases (Wang and Delwaide, 1995a). The adapted multiple point stimulation (AMPS)

\footnotetext{
* Corresponding author. Tel.: +32 4 2256401; fax: +32 42262939.
}

method is, in control subjects, an easier procedure devoid of methodological bias (Wang and Delwaide, 1995a,b); it has promise for ALS patients.

In the present study, we used first AMPS in 22 ALS patients to quantify denervation (motor unit number estimate: MUNE) at a particular moment in the evolution of this illness (cross-sectional evaluation) and to estimate the size of the remaining motor units (average surface-recorded motor unit action potential size: average S-MUAP size). After this first step, in 8 ALS patients, the thenar motor unit number and average S-MUAP size were estimated again (longitudinal evaluation), by using AMPS, after 2 and 6 months of treatment by a glutamate-release antagonist (riluzole).

\section{Methods and materials}

\subsection{Subjects}

Data were collected from 22 patients with ALS (12 men 
Table 1

Summary of observations on patients with ALS

\begin{tabular}{|c|c|c|c|c|c|c|c|c|c|c|}
\hline \multirow[t]{2}{*}{ Patient } & \multirow[t]{2}{*}{ Sex } & \multirow{2}{*}{$\begin{array}{l}\text { Age } \\
\text { (years) }\end{array}$} & \multirow[t]{2}{*}{ TMI } & \multicolumn{3}{|l|}{ MUNE } & \multicolumn{3}{|c|}{ Average S-MUAP size $(\mu \mathrm{V} \cdot \mathrm{ms})$} & \multirow{2}{*}{$\begin{array}{l}\text { Maximum M-poten- } \\
\text { tial size }(\mathrm{mV} \cdot \mathrm{ms})\end{array}$} \\
\hline & & & & I (LNL) & II & III & I (UNL) & II & III & \\
\hline 1 & M & 39 & 0 & $360(144)^{\mathrm{a}}$ & & & $87(154)^{\mathrm{a}}$ & & & $31.3(11.3)^{\mathrm{a}}$ \\
\hline 2 & $\mathrm{~F}$ & 51 & + & $22(119)$ & & & 278 (162) & & & $6.1(8.7)$ \\
\hline 3 & M & 72 & + & $66(86)$ & & & $181(180)$ & & & $11.9(4.1)^{\mathrm{a}}$ \\
\hline $4^{b}$ & M & 64 & + & $13(96)$ & & & $194(173)$ & & & $2.5(5.9)$ \\
\hline 5 & $\mathrm{~F}$ & 74 & 0 & $185(83)^{\mathrm{a}}$ & & & $112(182)^{\mathrm{a}}$ & & & $20.7(3.7)^{\mathrm{a}}$ \\
\hline 6 & M & 70 & + & $17(88)$ & & & $1250(178)$ & & & $21.3(4.6)^{\mathrm{a}}$ \\
\hline 7 & M & 76 & + & $50(80)$ & & & $169(184)^{\mathrm{a}}$ & & & $8.5(3.5)^{\mathrm{a}}$ \\
\hline 8 & $\mathrm{~F}$ & 70 & + & $41(88)$ & & & $244(178)$ & & & $10(4.6)^{\mathrm{a}}$ \\
\hline 9 & M & 47 & + & $6(127)$ & & & $1167(160)$ & & & $7(9.5)$ \\
\hline 10 & $\mathrm{~F}$ & 70 & + & $17(88)$ & & & $353(178)$ & & & $6(4.6)^{\mathrm{a}}$ \\
\hline $11^{\mathrm{b}}$ & M & 54 & + & $5(114)$ & & & $252(165)$ & & & $1.3(8)$ \\
\hline 12 & M & 70 & 0 & $81(88)$ & & & 307 (178) & & & $24.9(4.6)^{\mathrm{a}}$ \\
\hline $13^{\mathrm{b}}$ & $\mathrm{F}$ & 77 & + & 4 (79) & & & $221(185)$ & & & $0.9(3.1)$ \\
\hline 14 & M & 36 & + & $20(150)$ & 16 & 9 & 464 (152) & 409 & 794 & $9.3(11.9)$ \\
\hline $15^{\mathrm{b}}$ & $\mathrm{F}$ & 48 & + & $3(125)$ & 3 & 1 & $228(160)$ & 129 & 238 & $0.7(9.3)$ \\
\hline 16 & $\mathrm{~F}$ & 72 & + & $26(86)$ & 10 & 10 & $293(180)$ & 307 & 157 & $7.6(4.1)^{\mathrm{a}}$ \\
\hline 17 & $\mathrm{~F}$ & 58 & + & 6 (107) & 3 & 3 & 923 (168) & 982 & 944 & $5.5(7.2)$ \\
\hline 18 & $\mathrm{~F}$ & 65 & + & $35(95)$ & 17 & 9 & 339 (174) & 404 & 540 & $11.9(5.6)^{\mathrm{a}}$ \\
\hline 19 & M & 73 & 0 & $215(84)^{\mathrm{a}}$ & & & $116(181)^{\mathrm{a}}$ & & & $24.9(3.9)^{\mathrm{a}}$ \\
\hline 20 & M & 58 & + & 13 (107) & 6 & 3 & $363(168)$ & 888 & 2265 & $4.7(7.2)$ \\
\hline 21 & M & 46 & 0 & $149(129)^{a}$ & 104 & 81 & $150(159)^{\mathrm{a}}$ & 212 & 284 & $22.4(9.7)^{\mathrm{a}}$ \\
\hline 22 & $\mathrm{~F}$ & 68 & 0 & $143(91)^{a}$ & $114^{\mathrm{a}}$ & 70 & $73(177)^{\mathrm{a}}$ & 184 & 238 & $10.4(5)^{\mathrm{a}}$ \\
\hline
\end{tabular}

I, II, III = respectively before and after 2 and 6 months of riluzole therapy. MUNE, motor unit number estimate; S-MUAP, surface-recorded motor unit action potential; TMI, thenar muscle involvement (clinical amyotrophy and classical electromyographic signs of motor denervation).

${ }^{\text {a}}$ Value within lower and upper normal limits (LNL and UNL) related to age.

${ }^{\mathrm{b}} \mathrm{ALS}$ patients bed-ridden at the time of the study who died a few months later (terminal clinical stage).

and 10 women), after having obtained their informed consent; age ranged from 36 to 77 years (mean $62 \pm 13$ ) (Table 1). These patients fulfilled clinical and electrophysiological criteria for definite ALS (Brooks, 1994). None of the patients suffered from any additional pathology which would give rise to neuropathic or myopathic changes. At the start of the study none received drug therapy; but later, 8 patients received riluzole and a thenar motor unit number and average S-MUAP size estimation were realized after 2 and 6 months of treatment.

Table 1 summarizes clinical and electrophysiological observations in the 22 ALS patients. Four patients (patients 4,11, 13 and 15) were bed-ridden at the time of the study and died a few months later (terminal clinical stage). When AMPS was applied, 6 patients (patients 1, $5,12,19,21$ and 22) had neither clinical amyotrophy nor electrophysiological evidence of thenar muscle involvement.

Results in patients were compared with those published earlier from 70 healthy control subjects of both sexes and different ages ranging from 19 to 93 years (mean $50 \pm 20$ ) (Wang and Delwaide, 1995a,b). As the 3 studied variables (MUNE, average S-MUAP size, maximum Mpotential size) depend on age, each patient result was assessed by comparing it with the normal limits in terms of age (Fig. 1).

\subsection{AMPS technique}

The number and relative size of thenar motor units were estimated by the AMPS technique. This method, with its advantages and its reliability, has been presented in detail in an earlier paper (Wang and Delwaide, 1995a). With AMPS, the motor unit size was estimated by collecting and averaging 10 well identified S-MUAPs after stimulation at distinct points along the course of the median nerve between the wrist and elbow. At each stimulation site, only two or 3 S-MUAPs were evoked by incremental stimulation. To avoid alternation and ensure that any increment of the motor response corresponded to the activation of one single motor unit, S-MUAPs had to be evoked in an all-or-nothing, orderly and reproducible manner, with distinct thresholds and without any fractionation of the compound motor responses to successive identical stimuli. By dividing the maximum M-potential size by the average SMUAP size, a MUNE was obtained. Negative peak area measurements (from the onset of the first negative peak until the first crossing with the baseline) were selected to evaluate motor unit sizes and maximum M-potential sizes. Motor unit potentials that were predominantly or entirely positive in configuration were rejected from the analysis as these potentials were not supposed to be elicited by motor units with end-plates close to the stigmatic electrode. Small 


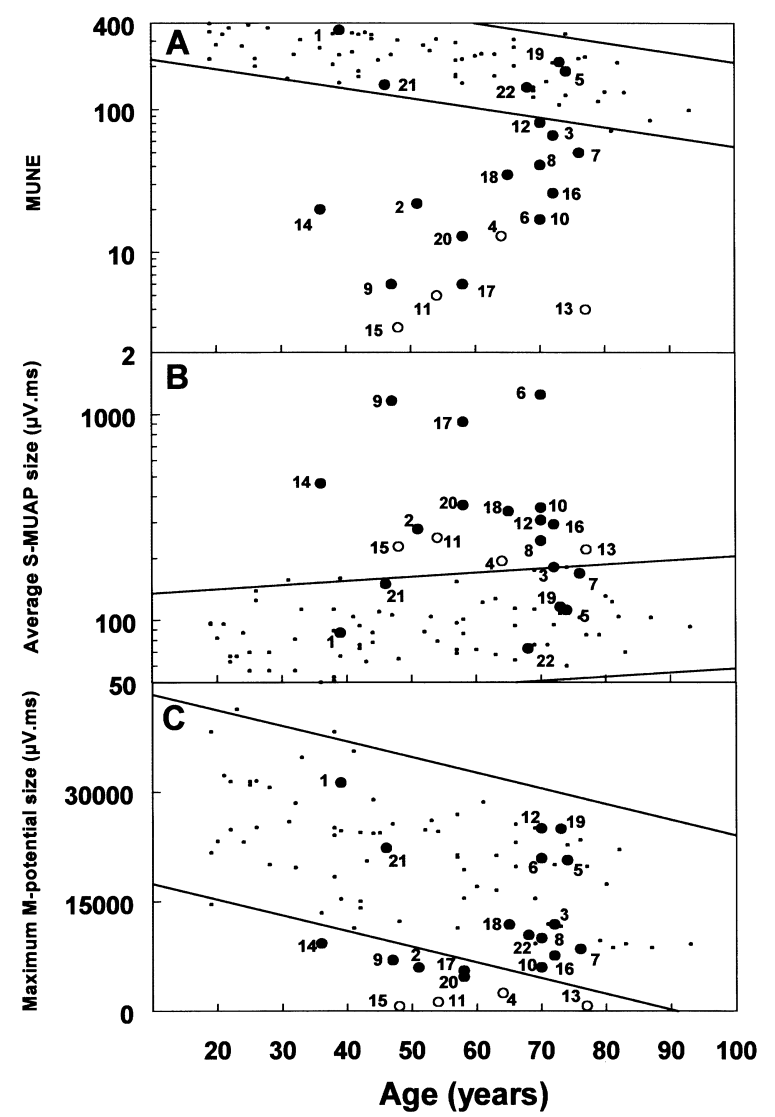

Fig. 1. Motor unit number estimate (MUNE) (A), average surface-recorded motor unit action potential (S-MUAP) size (B), and maximum M-potential size $(\mathrm{C})$ in terms of age in normal subjects (small circles) and amyotrophic lateral sclerosis (ALS) patients (dots; large circles = ALS patients at the terminal stage). In controls, prediction limits with a $P$-level of 0.05 give the lower and upper normal limits. (A) Three patients had thenar MUNE within normal limits, all the others had MUNE below the lower normal limit including even patient 12 who did not have clinical and classical electrophysiological evidence of thenar muscle involvement. (B) Four patients had thenar average S-MUAP sizes within normal limits while the others had motor unit sizes above the upper normal limit. In patients with ALS in a terminal clinical stage, average S-MUAP size was increased only moderately. (C) Eleven patients had maximum M-potential size within normal limits. Only 9 patients, in particular those with ALS in a terminal clinical stage, had maximum M-potential sizes less than the lower normal limit.

motor unit potentials with an initial positive phase, likely recorded from the lumbrical muscles, were also rejected.

All studies were performed on a Nicolet Viking I EMG machine (Nicolet Instrument Corp.). S-MUAPs were evoked by stimuli of $0.05 \mathrm{~ms}$ duration, delivered by surface electrodes (Medelec model LBS 53051; inter-electrode distance: $2.5 \mathrm{~cm}$ ) at $1 \mathrm{~Hz}$ with gradually increased intensity from a subthreshold value with incremental steps of $0.1-0.5$ mA. Motor responses were recorded (band-pass: $20 \mathrm{~Hz}-5$ $\mathrm{KHz}$ ) with surface electrodes (silver foils, $6 \mathrm{~cm}$ long and 0.8 $\mathrm{cm}$ wide). The stigmatic electrode was placed as close as possible to the thenar muscle end-plates. The reference electrode was attached over the proximal phalanx of the thumb.
The ground electrode was fixed over the dorsum of the wrist. The hand temperature was maintained above $30^{\circ} \mathrm{C}$.

\subsection{Conventional EMG and nerve conduction study}

All patients underwent motor and sensory nerve conduction measurements in upper and lower limbs bilaterally and concentric needle recordings from at least 3 limbs including the thenar muscles where MUNEs were obtained. In the present study, thenar muscle involvement was established if fibrillation potentials and/or large amplitude and duration motor unit action potentials were recorded.

\subsection{Statistical analysis}

Mean values have been expressed with their standard deviations. The significance of differences between means was determined by Student's $t$ tests for independent samples or paired Student's $t$ tests. When the variable under study evolved exponentially, a logarithmic transform of the values preceded Student's $t$ tests. Correlations between results, and results and age, have been calculated with regression analyses. Reproducibility of AMPS in ALS patients was estimated by the coefficient of variation between data collected on two successive trials.

\section{Results}

\subsection{AMPS in ALS patients}

Application of AMPS in ALS patients requires some comments. Theoretically, in case of pronounced motor denervation, it might be more difficult to find enough points from which to evoke distinct S-MUAPs than in normal subjects. In practice, however, and in particular in this study, it was easier to derive MUNEs in ALS patients than in healthy volunteers. Indeed, as previously reported (Brown and Milner-Brown, 1976), there is less overlap of motor unit thresholds when denervation is severe and, therefore, alternation is less noticeable. When the motor unit number is very low, it may sometimes be better to evoke more than 3 S-MUAPs without alternation from the same point using incremental stimulation. Therefore, two or 3 different stimulation points along the course of the median nerve are enough to derive an MUNE. If there are less than 10 motor units remaining in some patients, the best way to derive a MUNE is sometimes to find one stimulation point from which it is possible to activate the few remaining motor units without alternation. In these particular cases (5 patients in the present study), AMPS is very similar to the initial estimation technique described by McComas et al. (1971a).

\subsection{Test/retest reliability}

In 10 ALS patients, the thenar MUNE and average S- 

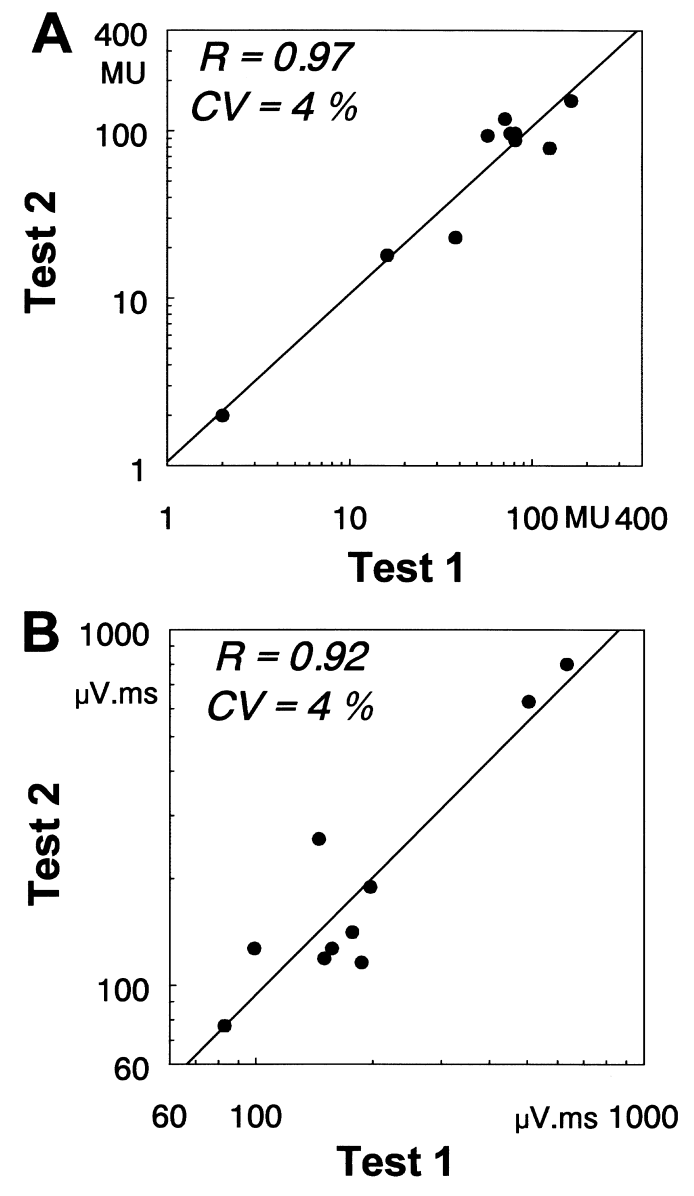

Fig. 2. Reproducibility of the adapted multiple point stimulation method assessed by the coefficient of variation between data collected on two successive trials (test 1 and test 2 ) from 10 amyotrophic lateral sclerosis patients. (A) Motor unit number estimates from the two trials were significantly correlated $(r=0.97, P<0.001)$ and the coefficient of variation (CV) was $4 \%$. (B) Average surface-recorded motor unit action potential sizes from the two trials were also significantly correlated $(r=0.92$, $P<0.001)$ and the $\mathrm{CV}$ was $4 \%$.

MUAP size were evaluated twice in the same session using AMPS by the same examiner after removal and replacement of surface recording electrodes for second trial. Results of MUNEs from the two trials were significantly correlated $(r=0.97, P<0.001)$ and the calculated coefficient of variation was $4 \%$ (Fig. 2A). Results of average S-MUAP sizes from the two trials were also correlated $(r=0.92$, $P<0.001)$ and the calculated coefficient of variation was $4 \%$ (Fig. 2B).

\subsection{Cross-sectional evaluation}

\subsubsection{Number of motor units}

The mean thenar MUNE in the 22 ALS patients was $67.1 \pm 90.6$ motor units (range: 3-360). In comparison with the mean thenar MUNE in volunteers (263.3 \pm 116.8), Student's $t$ test indicated a highly significant difference $(t=11.1, P<0.001)$ (Table 2$)$.

It can be seen from Table 1 and Fig. $1 \mathrm{~A}$ that, among the 22 patients with ALS, only 5 (patients 1, 5, 19, 21 and 22) had thenar MUNE within normal limits according to age. When AMPS was applied, these 5 patients had no clinical and electromyographic evidence of thenar muscle involvement. All the other patients had MUNE less than the lower normal limit. This was true even for patient 12 who, on the basis of clinical and classical electrophysiological examinations, did not seem to have thenar muscle involvement.

\subsubsection{Size of motor units}

The mean average S-MUAP size in the 22 ALS patients was $352.9 \pm 328.4 \mu \mathrm{V} \cdot \mathrm{ms}$ (range: $73-1250$ ). The maximum individual motor unit size was $3634 \mu \mathrm{V} \cdot \mathrm{ms}$. Thus, the mean average S-MUAP size in ALS was 4 times normal (94.1 $\mu \mathrm{V} \cdot \mathrm{ms}$ ) while some S-MUAPs were as much as 39 times normal. This indicated that some motor unit sizes remained within normal limits while others became extremely large. Fig. 3, which represents the distribution of the individual motor unit sizes in thenar muscles from each control subject and ALS patient, confirms that, in ALS, it was not uncommon for some motor unit potentials to increase much more in size than others. Student's $t$ test revealed that the difference between the mean in ALS and that in normal subjects $(94.1 \pm 30.3)$ was also highly significant $(t=9.8, P<$ 0.001 ) (Table 2).

Table 1 and Fig. 1B show that 6 patients (patients 1, 5, 7, 19, 21 and 22) had average S-MUAP size within normal limits. MUNE in patients 1, 5, 19, 21 and 22 was also, as mentioned above, within normal limits, while patient 7 had a decreased MUNE. The 16 other patients had motor unit sizes above the upper limit of normal. However, in patients 4, 11, 13 and 15 (ALS at a terminal clinical stage), average S-MUAP size was increased only moderately.

\subsubsection{Size of maximum M-potentials}

The mean thenar maximum M-potential size in the 22

Table 2

Comparison of AMPS results from normal subjects and ALS patients (means \pm SD)

\begin{tabular}{lccc}
\hline Variables & Normal subjects $(n)$ & ALS patients $(n)$ & Student's $t$ test \\
\hline Motor unit number estimate & $263.3 \pm 116.8(70)$ & $67.1 \pm 90.6(22)$ & $t=11.1^{*}$ \\
Average surface-recorded motor unit & $94.1 \pm 30.3(70)$ & $352.9 \pm 328.4(22)$ & $t=9.8^{*}$ \\
$\quad$ action potential size $(\mu \mathrm{V} \cdot \mathrm{ms})$ & $21.9 \pm 7.7(70)$ & $11.4 \pm 8.9(22)$ & $t=5.4^{*}$ \\
Maximum M-potential size $(\mathrm{mV} \cdot \mathrm{ms})$ & & \\
\hline
\end{tabular}

$* P<0.001$ 


\section{A Control Subjects}

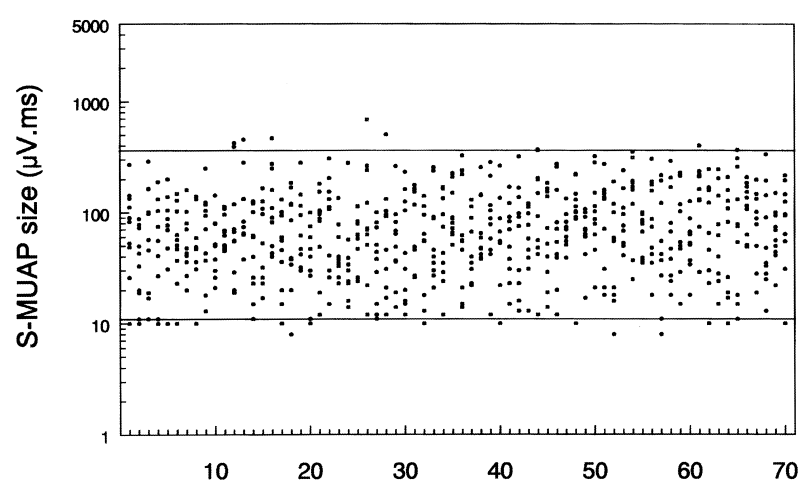

B ALS Patients

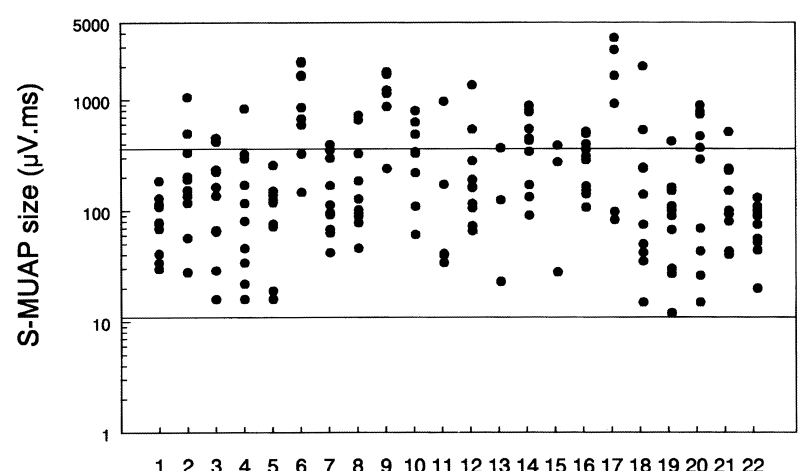

Fig. 3. Distribution of the individual surface-recorded motor unit action potential sizes: (A) in 70 control subjects; and (B) in 22 amyotrophic lateral sclerosis patients. The two SD limits outside the mean value give the lower and upper normal limits.

ALS patients was $11.4 \pm 8.9 \mathrm{mV} \cdot \mathrm{ms}$ (range: $0.7-31.3$ ). When compared with the mean thenar maximum M-potential in volunteers $(21.9 \pm 7.7)$, there was a significant difference $(t=5.4, P<0.001)$ (Table 2).

As shown in Table 1 and Fig. 1C, 13 ALS patients had maximum M-potential sizes within normal limits. Nine patients, in particular those with ALS in a terminal clinical

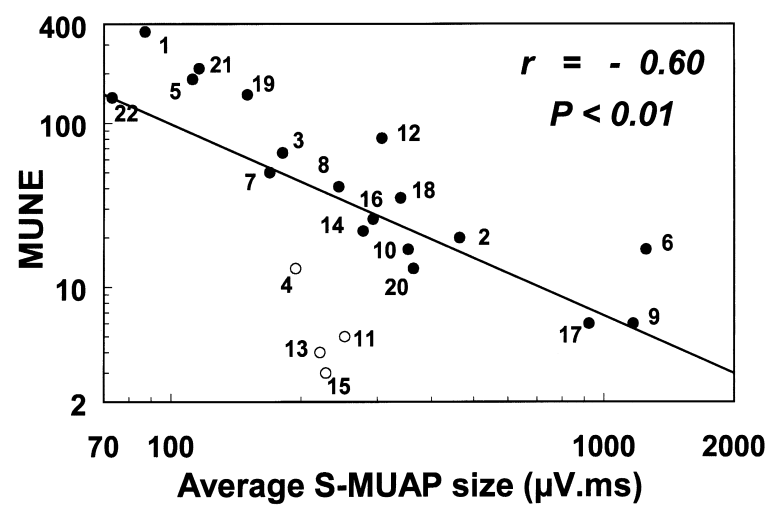

Fig. 4. Relationship between motor unit number estimate (MUNE) and average surface-recorded motor unit action potential (S-MUAP) size in amyotrophic lateral sclerosis (ALS) patients (circles = patients with ALS at a terminal clinical stage).
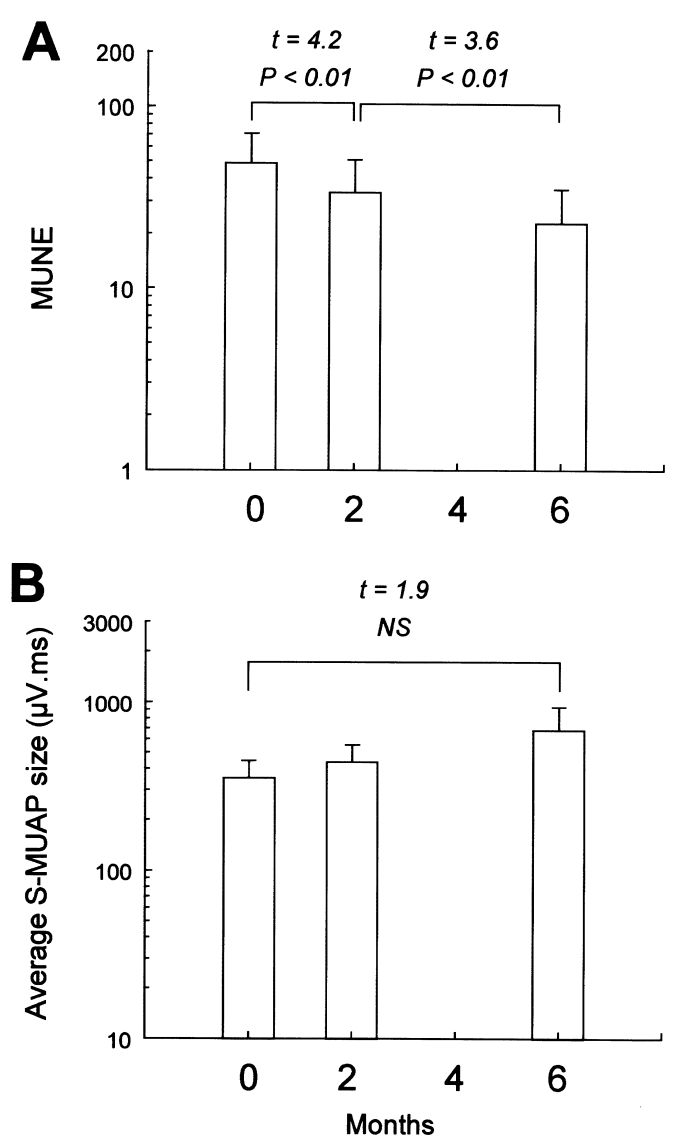

Fig. 5. Adapted multiple point stimulation results obtained from 8 amyotrophic lateral sclerosis patients before and after 2 and 6 months of a glutamate-release antagonist (riluzole) treatment. (A) Mean motor unit number estimates (MUNEs). (B) Mean average surface-recorded motor unit action potential (S-MUAP) sizes (standard errors of the mean indicated by bars).

stage (patients 4,11,13 and 15), had maximum M-potential sizes less than the lower normal limit.

\subsubsection{Relationship between MUNE and average S-MUAP size}

Fig. 4 shows that there was a statistically significant relationship between MUNE and average S-MUAP size $(r=-0.60, P<0.01, \ln Y=9.97-1.17 \ln X)$. Thus, low MUNEs were associated with high average S-MUAP sizes and vice versa. Fig. 4 also indicates that the 4 patients with ALS in a terminal clinical stage (patients 4,11,13 and 15) did not behave like other patients. Indeed, in these patients, the average S-MUAP size was lower than the size expected from the thenar MUNE. The disease duration, from the time of first reported symptoms, in these patients was 48, 36, 96 and 84 months respectively.

\subsection{Longitudinal evaluation}

Fig. 5 shows AMPS results obtained from 8 ALS patients (patients 14, 15, 16, 17, 18, 20, 21 and 22) who were studied 
repetitively before and after 2 and 6 months of riluzole therapy.

\subsubsection{Number of motor units}

At the start, mean thenar MUNE was $49.4 \pm 60.5$ motor units; after 2 months of treatment, mean MUNE was $34.1 \pm 46.6$ motor units. Paired Student's $t$ test indicated a significant difference between these two means $(t=4.2, P<0.01)$ (Fig. 5A). The mean thenar MUNE after 6 months of treatment was $23.3 \pm 32.6$ motor units. In comparison with the mean thenar MUNE after 2 months of treatment, paired Student's $t$ test also indicated a significant difference $(t=3.6, P<0.01)$ (Fig. 5A). The mean loss of motor units over 6 months of treatment reached $53 \%$.

\subsubsection{Size of motor units}

Before treatment, mean average S-MUAP size was $354.1 \pm 260.9 \mu \mathrm{V} \cdot \mathrm{ms}$. After 2 and 6 months of riluzole therapy, this mean value reached $439.4 \pm 322.6$ $\mu \mathrm{V} . \mathrm{ms}$ and $682.5 \pm 700.6 \mu \mathrm{V} \cdot \mathrm{ms}$ respectively. Paired Student's $t$ test indicated no significant difference between the different means (Fig. 5B). However, it can be seen from Table 1 that 5 ALS patients (patients 17, 18, 20, 21 and 22) presented a progressive average S-MUAP size increase after 2 and 6 months of treatment; while an average S-MUAP size decrease was observed in two patients (patients 14 and 15) after 2 months of treatment and in one patient (patient 16) after 6 months of treatment.

\section{Discussion}

As indicated in the results, AMPS in ALS patients is manageable and easier to do than expected even if the denervation is severe. Moreover, when thenar motor unit number and average S-MUAP size are estimated on two successive trials in the same patients, the results are reproducible (Fig. 2).

\subsection{Cross-sectional study}

Several motor unit counting methods have shown progressive loss of functioning motor units with advance of ALS (McComas et al., 1971a,b; McComas et al., 1973; Brown and Jaatoul, 1974; Sica et al., 1974; Hansen and Ballantyne, 1978; Daube, 1988; Strong et al., 1988; Dantes and McComas, 1991; Bromberg, 1993). From this point of view, AMPS is particularly appropriate to approach quantitatively the motor unit loss which characterizes ALS. Indeed, only 5 patients (patients $1,5,19,21$ and 22) have their motor unit numbers within normal limits at the moment of examination (Table 1 and Fig. 1A). Moreover, when AMPS is applied, these 5 patients have no sign of motor denervation in hand muscles and a diagnosis of
ALS is made on the basis of clinical and electrophysiological signs in other parts of the body. In patient 12 , there is no evidence of thenar muscle involvement either but MUNE is less than the lower normal limit. Thus, decreased MUNE is probably one of the most sensitive signs of motor denervation. From this point of view, it would be useful to make comparisons between the thenar strength as measured clinically, the findings on needle electromyography and the parameters derived by AMPS. However, Bromberg et al. (1993) have already shown, by making comparisons between MUNE values, isometric strength, compound muscle action potential (CMAP) amplitude, S-MUAP amplitude, fiber density, macro-EMG potential amplitude, turns-to-amplitude ratio, amplitude and recruitment pattern of low threshold voluntary motor units in ALS, that MUNE measurements are best suited to provide insight into the true natural history of the disease process and may be clinically useful to follow progression and response in drug trials. More recently, by comparing MUNEs, mean thenar S-MUAPs and CMAPs, isometric hand grip strength, total Medical Research Council manual muscle testing score, Appel ALS rating scale and force vital capacity, Felice (1997) concluded that MUNE values were the most sensitive index for documenting changes in disease progression over time.

By using different electrophysiological techniques, various authors demonstrated that mean motor unit potential area increased in ALS to 2-4 times normal and the maximum motor unit size until 57 times normal (McComas, 1977; Hansen and Ballantyne, 1978; Stålberg and Sanders, 1984; Strong et al., 1988). Our data on S-MUAP size confirm on average that in ALS, the motor unit size increased progressively with loss of motor units (Table 1, Figs. 1B and 4). However, the motor unit size increase is not uniform. Some motor units remain within normal size limits but others become extremely large (Fig. 3). This is not surprising since ALS must be considered a dynamic pathological process, lasting generally for a few years, during which death of one motorneuron leads to collateral reinnervation restricted to the remaining motor units in its close vicinity.

The relationship between MUNE and the average SMUAP size (Fig. 4) indicates that in the 4 patients with ALS in a terminal clinical stage (patients 4, 11, 13 and $15)$, the motor unit size increase is less important than in other patients. This fact might result from a methodological bias consisting of taking into account the small responses which might be evoked from distant motor units such as the lumbrical muscles. However, motor responses from distant units were characterized by an initial positive phase and were rejected from the analysis. Thus, two hypotheses must be considered to explain low average S-MUAP sizes estimated in these 4 patients. Either these patients suffer from a particularly acute form of ALS and collateral reinnervation is less efficacious in compensating for motor denervation, or there is a secondary motor unit size 
decrease. The disease duration, from the time of first reported symptoms, in these patients $(48,36,96,84$ months, respectively) does not argue in favor of an acute form of ALS. In a recent longitudinal study in ALS patients, Emeryk-Szajewska et al. (1997) have well documented the biphasic MUAP amplitude and area evolution. They confirmed that reinnervation was able to compensate for the loss of over $50 \%$ of motor units; but only transitorily. Indeed in later stages, single MUAP parameters such as amplitude and area decreased and sometimes fell close to normal values. This result leads to the following comment: if the average S-MUAP size in a patient with ALS is within normal limits, either the studied muscle is healthy, or the disease is severely decompensated without effective collateral reinnervation.

Values of maximum M-potential confirm that collateral reinnervation is able, from an electrophysiological point of view, to compensate for motor denervation. Indeed, 13 patients kept their maximum M-potential size within normal limits (Fig. 1C). However, in the terminal clinical stage of ALS, motor denervation is no longer compensated. In this case, the maximum M-potential size falls below the lower normal limit. Thus, maximum M-potential size might be considered as an electrophysiological clue about ALS compensation or decompensation.

\subsection{Longitudinal study}

In the $8 \mathrm{ALS}$ patients under riluzole therapy, a dramatic accelerated loss of motor units (53\% after 6 months of treatment) is measured (Fig. 5A), which contrasts with the physiological loss of motor units (1.3\% per year) (Wang and Delwaide, 1995a). As there was no comparison possible with patients not under riluzole - a protocol more and more difficult from an ethical point of view - no conclusion can be drawn concerning efficacy of this treatment; however such a double blind study would be welcome.

The mean motor unit size does not significantly increase (using paired Student's $t$ test) after 6 months of treatment. However, in 5 patients (patients 17, 18, 20, 21 and 22) average S-MUAP size progressively increases after 2 and 6 months of treatment while in 3 patients average S-MUAP size decreases either after 2 (patients 14 and 15) or 6 (patient 16) months of treatment (Table 1). These surprising sequential S-MUAP size changes might be related to technical changes due, for instance, to variation in recording electrode placement. However, the reproducibility of AMPS results evaluated by a test/retest reliability (Fig. 2) implied the removal and replacement of surface recording electrodes for the second trial. Thus, the average S-MUAP size decrease observed in these 3 patients might rather reflect again the dynamic aspect of ALS and might indicate 'disintegration' of motor units reinnervated at earlier stages (Emeryk-Szajewska et al., 1997) or the loss of some particularly large motor units.

\section{Acknowledgements}

The authors thank P. Gérard and V. De Pasqua for their valuable technical assistance.

\section{References}

Bromberg, M.B. Motor unit estimation: reproducibility of the spike-triggered averaging technique in normal and ALS subjects. Muscle Nerve, 1993, 16: 466-471.

Bromberg, M.B., Forshew, D.A., Nau, K.L., Bromberg, J., Simmons, Z. and Fries, T.J. Motor unit number estimation, isometric strength, and electromyographic measures in amyotrophic lateral sclerosis. Muscle Nerve, 1993, 16: 1213-1219.

Brooks, B.R. World Federation of Neurology criteria for the diagnosis of amyotrophic lateral sclerosis. J. Neurol. Sci., 1994, 124 (Suppl.): 96107.

Brown, W.F. and Jaatoul, N. Amyotrophic lateral sclerosis. Electrophysiologic study (number of motor units and rate of decay of motor units). Arch. Neurol., 1974, 30: 242-248.

Brown, W.F. and Milner-Brown, H.S. Some electrical properties of motor units and their effects on the methods of estimating motor unit numbers. J. Neurol. Neurosurg. Psychiatry, 1976, 39: 249-257.

Cornblath, D.R., Kuncl, R.W., Mellits, E.D., Quaskey, S.A., Clawson, L., Pestronk, A. and Drachman, D.B. Nerve conduction studies in amyotrophic lateral sclerosis. Muscle Nerve, 1992, 15: 1111-1115.

Dantes, M. and McComas, A. The extent and time course of motoneuron involvement in amyotrophic lateral sclerosis. Muscle Nerve, 1991, 14: 416-421.

Daube, J.R. Statistical estimates of number of motor units in thenar and foot muscles in patients with amyotrophic lateral sclerosis or the residual of poliomyelitis. Muscle Nerve, 1988, 11: 957.

Emeryk-Szajewska, B., Kopeć, J. and Karwanska, A. The reorganization of motor units in motor neuron disease. Muscle Nerve, 1997, 20: 306315.

Felice, K.J. A longitudinal study comparing thenar motor unit number estimates to other quantitative tests in patients with amyotrophic lateral sclerosis. Muscle Nerve, 1997, 20: 179-185.

Hansen, S. and Ballantyne, J.P. A quantitative electrophysiological study of motor neurone disease. J. Neurol. Neurosurg. Psychiatry, 1978, 41: $773-783$

Lambert, E.H. Electromyography in amyotrophic lateral sclerosis. In: F.H. Norris Jr. and L.T. Kurland (Eds.), Motor Neuron Diseases: Research on Amyotrophic Lateral Sclerosis and Related Disorders. Grune and Stratton, New York, 1969, pp. 135-153.

McComas, A.J. Neuromuscular Function and Disorders. Butterworths, London, 1977.

McComas, A.J., Fawcett, P.R.W., Campbell, M.J. and Sica, R.E.P. Electrophysiological estimation of the number of motor units within a human muscle. J. Neurol. Neurosurg. Psychiatry, 1971a, 34: 121131.

McComas, A.J., Sica, R.E.P., Campbell, M.J. and Upton, A.R.M. Functional compensation in partially denervated muscles. J. Neurol. Neurosurg. Psychiatry, 1971b, 34: 453-460.

McComas, A.J., Upton, A.R.M. and Sica, R.E.P. Motoneurone disease and ageing. Lancet, 1973, 29: 1477-1480.

Sica, R.E.P., McComas, A.J., Upton, A.R.M. and Longmire, D. Motor unit estimations in small muscles of the hand. J. Neurol. Neurosurg. Psychiatry, 1974, 37: 55-67.

Stålberg, E. and Sanders, D.B. The motor unit in amyotrophic lateral sclerosis studied with different neurophysiological techniques. In: F.C. Rose (Ed.), Research Progress in Motor Neurone Disease. Pitman, London, 1984, pp. 105-121.

Strong, M.J., Brown, W.F., Hudson, A.J. and Snow, R. Motor unit esti- 
mates in the biceps-brachialis in amyotrophic lateral sclerosis. Muscle Nerve, 1988, 11: 415-422.

Swash, M. and Schwartz, M.S. A longitudinal study of changes in motor units in motor neuron disease. J. Neurol. Sci., 1982, 56: 185197.

Wang, F.C. and Delwaide, P.J. Number and relative size of thenar motor units estimated by an adapted multiple point stimulation method. Muscle Nerve, 1995a, 18: 969-979.

Wang, F.C. and Delwaide, P.J. An adapted multiple point stimulation (AMPS) method for estimating the number and size of motor units. Electroencephalogr. clin. Neurophysiol., 1995b, 97: S164. 